\title{
A Statistical Approach for Analyzing Residential Isolation and its Determinants for Immigrant Communities: an Application to the Montréal Metropolitan Region
}

\author{
Guillaume Marois $^{1,2}$ (D) Sébastien Lord ${ }^{1}$
}

Received: 19 August 2016 / Accepted: 31 March 2017 /

Published online: 21 April 2017

C) The Author(s) 2017. This article is an open access publication

\begin{abstract}
The aim of this paper is to measure the net propensity to live in isolation for Montréal's main immigrant communities and to identify specific profiles that are particularly isolated. For that purpose, a statistical approach is used based on individual determinants to compute standardized isolation indexes that take into account the socioeconomic composition of the different groups. The models we developed also reveal how individuals' characteristics, such as generational status, date of migration, education, language abilities or income, affect their residential isolation. Results reveal that many individual characteristics have strong impacts on residential isolation, and that those impacts are not always the same among immigrant communities. Also, the low propensity to live in isolation observed for all immigrant communities suggests that the place stratification model is probably not relevant to explain the residential dynamics of immigrant communities in Montréal. However, some vulnerable groups are much more likely to live in isolation: Haitian and South Asian with low education, low-income Maghrebis, and Filipinos who arrived via the Live-in Caregivers program. Some wealthy groups are also more isolated, such as Italians arrived before 1981. Therefore, considering this wide heterogeneity among immigrant communities, studies on their residential dynamic should not consider them as a whole.
\end{abstract}

Keywords Migration · Housing location· Segregation · Isolation · Montréal

Guillaume Marois

marois@iiasa.ac.at

Sébastien Lord

sebastien.lord@umontreal.ca

1 International Institute for Applied Systems Analysis (IIASA), Schlossplatz 1, A-2361, Laxenburg, Austria

2 École d'urbanisme et d'architecture de paysage, Université de Montréal, CP 6128 Succursale Centre-ville, Montréal, (Québec) H3C 3J7, Canada 


\section{Introduction}

International migration is a metropolitan phenomenon in some geographical areas that affects a significant number of individuals (Faist 2000). We observe high concentrations of people in specific places with highly differentiated social and economic capital (Sassen 1991). In the Greater Montréal region (in the province of Québec, Canada), immigration is obvious in central areas of the city, but also exists in certain first-ring suburbs. Montréal is the destination of about $85 \%$ of those who immigrate to Québec (Institut de la statistique du Québec 2015). As such, the Montréal region has high levels of immigration and international mobility (Apparicio and Séguin 2002; Canada 2013) and communities of foreign origin which have existed for generations (Germain et al. 2012). International immigration has influenced the demographic makeup of Montréal for many decades. Montréal's cultural, ethnic, and religious diversities are striking, even though its concentrations of people with similar cultural backgrounds (which are often stigmatized) are less than many other North American or Western European metropolitan regions (Apparicio et al. 2006; Brown and Chung 2006).

Most researchers who study racial segregation and the spatial locations of immigrants and/or ethnic groups focus on the United States of America. They propose exogenous factors to explain their results, such as discrimination, housing markets, and group preferences (Johnston et al. 2004). Canadian cities can hardly be compared to American ones; the racial diversity in Canada is much more recent than in the United States and results from Canada's recent immigration policies rather than historical reasons. Unlike Canada's other metropolitan areas, Montréal has a unique ethnic context. Montréal is the only large North American city in which the French language is predominant (though it has an important and wealthy English-speaking minority, as well). The study of residential integration of immigrants in that context would thus provide new empirical knowledge on the subject matter. Apparicio et al. (2006) studied the segregation of Montréal's immigrant and ethnic communities by examining many segregation indicators to identify different dimensions of segregation: equality, concentration, and isolation. Although these researchers did not identify any hyperisolated immigrant communities in Montréal, their indicators are mainly descriptive and may not be adequate for assessing the individual determinants of segregated living. Furthermore, very isolated groups which combine many individual characteristics that foster a propensity for segregation could exist, although diluted in the gross isolation index of a larger group. In the context of residential segregation, we note the concurrent presence of immigrants with few integration "capabilities". This is connected to notions of economic, social, and cultural capital (Bourdieu 1979; 2000). Thus, disadvantaged immigrants must be distinguished from others who have more opportunity, especially in housing integration and ownership accession (Borjas 2002). As Iceland and Scopilliti (2008) noted, "it would be useful to look at patterns of specific groups in more detail, as there is much intragroup variation in both the historical context of immigration and the characteristics of the immigrants themselves" (p.93). This paper proposes an approach in response to this recommendation.

The aim of this paper is to measure the net propensity to live in isolation for Montréal's main immigrant communities and to identify specific profiles that are particularly isolated. Residential isolation is a key dimension of the segregation and refers to the spatial cohabitation among members of a same group (Johnston et al. 2004). We examined how individuals' characteristics of Montréal's main immigrant 
communities influence their segregation level. First, we discussed on methodological issues in regard to the calculation of a standardized isolation index that takes into account both size and composition of the communities. Following this discussion, we made an empirical demonstration of the standardized isolation index to measure immigrant communities' net propensities to live in segregation by performing statistical controls on sociodemographic characteristics, which may impact their residential locations. Finally, we identified the individuals' determinants of residential segregation, which then allows to identify specific profiles which are particularly isolated.

Residential choices are complex. This research, therefore, contributes to the understanding of residential choice by focusing on individuals' determinants of isolation using a statistical approach. We postulate that isolation can be explained by multiple factors related to individual characteristics as well as the interactions of the person with the city and communities. Montréal is a relevant study case, because, as explained below, its context allows controlling many variables of interest. In this way, the complexity and relativity of residential isolation are better approached.

\section{Litterature Review}

While the integration of immigrants involves many factors, including language, employment, and education, the issue of housing remains crucial for immigrants' residential trajectories and establishment (Séguin et al. 2003). For decades, urban segregation has involved both housing availability and housing conditions. Developed from the "Chicago School" and urban ecology approaches (Park and Burgess 1925), segregation and spatial patterns of immigrants' residential locations interested researchers for decades. Immigrants' integration into residential environments is thus well documented, providing well-known, rigorous, and validated interpretive frameworks at both "macro" and "micro" levels (Park and Burgess 1925; Massey and Denton 1985; Fong and Gulia 1999; Logan et al. 2002; Apparicio et al. 2006; Andersen 2010). According to the spatial assimilation model, immigrants first settle into segregated ethnic enclaves with poor housing conditions. As they ameliorated, over the years, their socioeconomic status and language abilities, they also improve their spatial location and housing situations and move to less segregated sectors. We should thus expect to observe a lower propensity to live in residential isolation for established and wealthier immigrants.

However, this trend could be altered when discrimination in the housing market or structural barriers interfere into the residential opportunities (Charles 2003), what scholars call the ethnic disadvantage model or the place stratification model. This pattern have been widely observed and documented for American metropolitan areas, where discriminatory practices from real estate agents and bank institutions as well as neighborhood hostility lead to a persistent segregation for Afro-Americans (Turner et al. 2002; Iceland and Scopilliti 2008; Iceland and Wilkes 2006). Although the racial segregation tended to decline over the last decades, Logan (2013) suggests that the residential behaviors of Whites could limit the progress toward multi-ethnic metropolis, because they tend to leave mixed neighborhoods and avoid areas where minorities are predominant.

More recently, many scholars also found that middle and upper class immigrants could have preference to live with their ethnic group, reflecting a natural ethnocentrism rather than social constraints or hostility between groups (Chung and Brown 2007; 
Brown and Chung 2008; Walton 2012; Wen et al. 2009; Charles 2003). This residential dynamic called resurgent ethnicity could maintain segregation or create resegregation. Similar to the ethnic disadvantage model regarding the spatial distribution of populations, in the resurgent ethnicity model, ethnic concentration is not necessarily associated with poor quality neighborhood, social disorganization and uneven access to amenities, particularly when the presence of well-educated people is appreciable (Galea and Ahern 2005).

Moreover, social relationships are not limited to the residential dimension, immigrants' residential proximity to other groups promotes their acculturation, linguistic skills, and exogenous unions (Apparicio 2000). Residential segregation has multiple meanings that make it difficult to explore merely with spatial differentiation (Brun et al. 1994). Whether segregation takes on the attributes of "ghettos" (with negative attributes) or "enclaves" (closer to the notion of withdrawal) these concentrations are similar geographical phenomena. These concentrations (objectively the same) imply different subjective experiences by immigrants (Balakrishnan and Hou 1999). On the one hand, spatial concentration can lead to negative effects such as limited access to urban resources and educational facilities. It can also imply exclusion from labor markets, higher dropout rates, higher levels of youth crime, and higher risks of stigmatization (Shihadeh and Flynn 1996; van Kempen, and şule Özüekren, A. 1998; Fitoussi et al. 2004; Karsten et al. 2006; Sélimanovski 2008). From this perspective, Johnston et al. (Johnston et al. 2002; Johnston et al. 2005) defined segregation as a pattern linked with social exclusion, unequal treatment and negative effects on feelings of selfesteem and identity among the minority population. On the other hand, the same residential segregation can be seen as a positive "resource" which allows immigrants to preserve their identities, languages, religions, and cultures (Dunn 1998; Peleman 2002; Simpson 2004). More broadly, segregation provides them with spatial differentiation that may actually facilitate their further integration.

As observed by Musterd et al. (1998), residential segregation (from the actor's standpoint) may be a strategy that hides another: the expectation of integration. If immigrants arrive into a well-established immigrant community where they can easily access social networks and cultural resources, the integration process, in general, and the housing market integration, in particular, can be much easier. However, less qualified immigrant groups with lower levels of social capital do not experience all the benefits of this concentration (Cutler et al. 2008). This perspective shows the limits of the theoretical and empirical frameworks connected to residential segregation.

Although common spatial segregation indicators provide detailed geographical descriptions of residential locations of the studied groups, they do not assess the individual determinants of segregated living and how individual characteristics of the immigrants affect their residential behavior (Spivak et al. 2011). As such, the segregation level might be considered low for animmigrant community as a whole, while one of its subpopulations is highly isolated. Moreover, owing to their descriptive nature, these indexes do not take into account groups' socioeconomic composition. For example, a community $\mathrm{A}$ in which most of members are new immigrants will probably have a higher isolation level than a community $\mathrm{B}$ in which most of members immigrated long time ago. This does not mean that member of community A have a higher propensity to live segregated, rather the difference between the observed segregation would be a group composition effect. This issue has been highlighted by Simpson (2004), who showed that the observed increase of the number of majority South Asian areas in UK is due the arrival of 
newcomers and natural growth rather than by a movement of South Asians toward those areas. Overall, using descriptive segregation indicators could lead to confound social trends as racial phenomenons. A descriptive approach trying to account for a variable such as socioeconomic status require the calculation of index for every category and for all studied groups (Spivak et al. 2011; Apparicio et al. 2006). This approach, however, become very complex when it comes to plenty of variables, particularly when there are interactions between them, such as income, education and year of immigration. Evidence of the effect of the groups' socioeconomic composition on segregation patterns are also exposed by macro-level regression models (Iceland and Scopilliti 2008; Iceland and Wilkes 2006; Hall 2013) using average group characteristics as independent variables, but none of these focused on the individual level.

\section{Methodology}

A widely used indicator of residential isolation is Bell's isolation index (Bell 1954; Apparicio 2000). This indicator represents the average proportion of people from the same group living in a given neighborhood. This refers to the exclusive presence of the same group in a neighbourhood - one of the main aspects of segregation. For an immigrant community $c$, the isolation index $I_{c}$ is defined by Eq. 1:

$$
I_{c}=\sum_{j=1}^{n}\left[x_{j c} / X_{c}\right]\left[x_{j c} / t_{j}\right]
$$

in which:

$\mathrm{x}_{\mathrm{jc}}$ is the population of community $c$ in neighborhood $j$;

$\mathrm{X}_{\mathrm{c}}$ is the population of community $c$ in the metropolitan region;

$\mathrm{t}_{\mathrm{j}} \quad$ is the total population of neighbhorhood $j$.

Thus, an index of 1 would indicate that all member of community c live a neighborhood where $100 \%$ of the population belong to the same community (complete isolation).

However, the proportion of the immigrant community in the metropolitan area affects this index, because the mean proportion of people of the same community will be higher for largest communities. In fact, if there was no segregation at all, $I_{c}$ would be the same as the proportion of the group in the total population, and largest communities would thus have highest indexes. To take into account the relative proportion of differents groups in a metropolitan area, the isolation index can be transformed to get the modified isolation index $M I_{c}$ (Bell 1954; Apparicio 2000), as defined by Eq. 2:

$$
M I_{c}=\left(I_{c}-X_{c} / T\right) /\left(1-X_{c} / T\right)
$$

in which $\mathrm{T}$ refers to the total population of the metropolitan region.

A $M I_{c}$ score close to 0 indicates that the proportion of community $c$ is the same across all neighbourhoods in a metropolitan area. However, if the index is closer to 1 , the group is more isolated. 
As explained above, the composition of immigrant communities could also have a significant impact on the isolation index (both gross and modified). To take this into account in order to get a standardized isolation index, we used an approach inspired by the "locational attainment model" (Alba and Logan 1992) In this model, a characteristic of neighborhoods is the dependent variable and individuals' characteristics are independent variables. Many studies use neighborhoods' median incomes or their proportion of "Whites" as dependent variables to determine if minority groups such as "Blacks" or "Hispanics" have the same access to desirable neighborhoods as "Whites" with similar characteristics (Logan et al. 1996; Myles and Hou 2003; Cort 2011; Glikman and Semyonov 2012). Fong and Chan (2010) built similar models using the proportion of the same community in the neighborhood as dependent variable to assess the net effect of economic resources, co-ethnic preferences, and the use of coethnic information sources on co-ethnic clustering.

Following this approach, in this study, we set as the dependent variable the proportion of the population in the neighborhood that belongs to the same immigrant community. For a community c, the model can be defined by Eq. 3:

$$
Y_{c}=\alpha_{c}+\beta_{1 c} X_{1 i c}+\beta_{2 c} X_{2 i c} \ldots+e_{i c}
$$

in which:

$Y_{c}$ is the proportion of the population in the neighborhood that belongs to community $c$

$X_{k i c}$ are a set of characteristics $k$ for an individual $i$ from community $c$;

$\beta_{k c}$ are the parameters of characteristics $k$ for community $c$.

When there are no independent variables, because the dependant variable is the proportion of the same community living in the neighborhood, the intercept $\alpha_{c}$ corresponds exactly to the isolation index described above, but calculated from disaggregated data (individual level) (Alba and Logan 1992). Calculating isolation indexes by regression methods furthermore provides confidence intervals that inform whether or not values result from a random process. Therefore, in Eq. 3, the parameters $\beta$ indicate the impact of related variables on the propensity to live in isolation. In other words, analysis of $\beta$ assess how individual characteristics affect communities' propensities to live in isolation. When there are a large number of characteristics, $\alpha_{c}$ can be considered as a standardized isolation index $\mathrm{SI}_{\mathrm{c}}$ (see Eq. 4), i.e. the isolation index for the specific profile of the reference categories of $X_{k}$. We can then determine which community is the most likely to live isolated for a standardized profile by comparing their respective $\alpha_{c}$. In our models, reference categories have been chosen prioritizing that they all count significant number of individuals for every community. Moreover, this statistical approach at the individual level gives confidence intervals for indexes which determine whether or not they differ significantly from each other.

$$
S I_{c}=\alpha_{c}
$$

in which:

$\alpha_{c} \quad$ is the intercept of Eq. 3 . 
As described in Eq. 5, by performing the same transformation to $\mathrm{SI}_{\mathrm{c}}$ as the one we used to get $M I_{c}$, we obtain a standardized modified isolation index $S M I_{c}$ which takes into account both the population composition and the proportion of the group.

$$
S M I_{c}=\left(S I_{c}-X_{c} / T\right) /\left(1-X_{c} / T\right)
$$

Locational attainment models may contain inconsistencies due to spatial autocorrelation because multiple individuals live in the same sector and thus have the same value on the dependent variable (Logan et al. 1996; Cort 2011; Pelletier 2012). This situation underestimates the standard error of parameters, because errors are correlated. Thus, as other authors making use of locational attainment models have suggested (Myles and Hou 2003; Cort 2011), we estimate parameters using the feasible generalized least squares method to generate standard errors that take into account the correlated error terms within neighborhoods (Greene 1997).

The second part of the analysis identifies specific profiles that display a higher propensity to live in isolated neighbourhoood. Using the results of multivariate analyses completed in the first part and taking into consideration the descriptive statistics of immigrant communities. The $\mathrm{SMI}_{\mathrm{c}}$ is for a specific profile that corresponds to the reference categories of independent variables. Thus, by adding to the $\mathrm{SMI}_{\mathrm{c}}$ selected specific characteristics' parameters, we get alternative isolation index for specific profiles.

\section{Data}

Our analysis requests a large individual database that contains residential location at a small geographical level and exhaustive individual characteristics, including an ethnic dimension. The most recent database that provides that kind of information is the 2011 National Household Survey (NHS) (Canada 2013). That database contains individual characteristics such as gender, age, family structure, income, education, year of immigration, language, etc., but also information on the place of birth of the respondent and his parents, which allows constructing immigrant communities based on the country of origin of the first and second generation. The NHS also divided the Montréal metropolitan area in 921 in sectors (census tracts) that can be used to define the neighborhood. However, the NHS replaced the long form census that is no longer mandatory. The response rate is about $70 \%$, but could vary widely between groups. Consequently, the non-response bias is likely to be larger for specific groups such as recent immigrants or those who don't speak French or English, which could underestimate their isolation rates. The NHS remains the most comprehensive Canadian data source on population and housing conditions. The 2006 mandatory long form Census has less bias, but is outdated; since then, more than 250,000 immigrants settled in the province of Québec, mainly in Montréal. Using this former census would reduce the relevance of analysis because the context has changed. However, with the return of the mandatory long form census in 2016, further investigations could be made to evaluate the plausible bias for vulnerable groups.

The Montréal metropolitan area has dozens of immigrant communities, making it impossible to analyze each individually. Thus our analyses focus on the main groups. 
For our purposes, an immigrant community consists of individuals living in a household where the breadwinner ${ }^{1}$ is either born abroad or has a parent who is born abroad. The basic principle behind the construction of communities is based on the country of birth of the breadwinner or his parents, depending of his generational status, either:

- Country of birth if born outside Canada;

- Country of birth of parents if both are born outside Canada, from the same country;

- Country of birth of the mother if both parents are born outside Canada, but from different country;

- Country of birth of the foreign-born parent if only one parent is born outside Canada.

We then regrouped countries that have contextual or geographical similarities and kept the 15 main immigrant communities, excluding those who come from France, England and USA for historical reasons. The characteristics are thus those of the breadwinner, which is the usual procedure for that kind of study (Rosenbaum and Friedman 2001; Myles and Hou 2003). This procedure allows a better accuracy on the residential location of the second generation. Otherwise these behaviors could be biased by children who still live with their parents (first generation).

\section{Descriptive Statistics of Immigrant Communities}

The 15 immigrant communities of the Montréal metropolitan region studied in this article are the following: Italian, Maghrebi, Haitian, Lebanese, Greek, Chinese, Vietnamese, Portuguese, Romanian, Filipino, South American, Central American, Sub-Saharan African, people from other Arabic countries, and South Asian. These communities represent 1.1 million people-about $30 \%$ of the population of the Montréal metropolitan area $(3,752,475)$. Each of these communities numbers at least 30,000 people. The Italian community is the largest $(167,000)$, followed by the Maghrebi $(140,000)$ and Haitian $(117,000)$ communities. In Appendix 1, we provide descriptive statistics of these communities.

Only Haitian, Central American, and Filipino communicities have similar proportions of males or females as breadwinner. Males are the predominant breadwinner in all other groups - particularly in the South Asian, Maghrebi, and Lebanese communities, and for people from other Arabic countries. The Filipino case may be due to the fact that many Filipinos immigrated to Montréal via the Live-In Caregivers program, which mainly recruits women. The predominance of female breadwinners in the Central American and Haitian groups may be due to their larger proportion of single-parent families $(25.1 \%$ and $29.5 \%$, while the proportion varies between $6.2 \%$ and $16.9 \%$ for other communities), which are typically led by women. On the other hand, the South

\footnotetext{
${ }^{1}$ The breadwinner refers to the primary household maintainer.
} 
Asian (75.1\%), Maghrebis (72.8\%), and Lebanese (69.5\%) had the largest proportions of couples with children, which can is probably related with their higher proportion of men as breadwinner.

Most people in the Italian (90\%) and Greek (80\%) communities immigrated before 1971 or are members of a second generation. Conversely, a large proportion of Montréal's Maghrebis, Chinese, Romanians, and Sub-Saharan Africans are recent immigrants. More than $40 \%$ of them arrived in the 2000 s and very few of them are born in Canada. Most Haitian and Vietnamese immigrants arrived between 1971 and 1990, in the wake of political unrest in their home countries. Many Lebanese and South Asian people came to Montréal in the $80 \mathrm{~s}$ and the 90s. These groups' time of arrival is reflected in the age of the breadwinner. The Italian and Greek communities are the oldest, with more than a quarter aged 65 and over; the proportion of elderly people among Maghrebis and Sub-Saharan Africans (more recent arrivals) is below 5\%.

Human capital, measured by education level and knowledge of official languages differs widely between immigrant communities. Romanian, Chinese, Maghrebi, and people from other Arabic countries are the most educated; nearly 50\% of these people who live in households in which the breadwinner has at least a bachor's degree. As noted above, these people are more recent immigrants; they enter Canada primarily as qualified workers. The oldest waves of immigration are the less educated since they arrived before the implementation of Canada's economic immigration programs. Many Portuguese, Greek, and Italian people live in households in which the breadwinner does not have a degree $(38.0 \%, 31.7 \%$, and $25.1 \%$, respectively); very few have university degrees $(11.8 \%, 18.9 \%$, and $18.7 \%$ ). Some communities consist of refugees; a high proportion of these people have little or no education, such as in the Vietnamese (25\%), Central American (22.8\%), South Asians (20.6\%), and Haitian (18.6\%) communities.

Many groups have a large proportion of people who know both English and French, specifically the Italian (81.3\%), Romanian (77.6\%), and Lebanese (76.6\%) communities. However, some groups are more likely to only know English, such as the Filipino (76.7\%), South Asian (66.6\%), and Chinese $(52.9 \%)$ communities. The only group in which fewer than half of people knew English was the Haitian community; however, 53\% of Haitians understand French only. In the Chinese (15.6\%) and the Vietnamese (11\%) communities, a notable proportion of people live in a household where the breadwinner did not understand either English or French; this number is marginal in the other communities we studied.

These communities are very heterogeneous in terms of their social capital, generational status, and time since arrival; we were not surprised to find that the distribution of population according to household' income quintile varied widely among these communities. The groups with the highest proportion in the poorest quintile are the Maghrebi (37.7\%), Sub-Saharan African (37.2\%), South Asian (35.8\%), and Central American communities (34.6\%). The groups with the highest proportions in the wealthiest quintile are the Italian $(22.6 \%)$, people from other Arabic countries (19.8\%) and Romanian (19.5\%) communities. The Italian community is the only group with an overall wealth greater than the Montréal Metropolitan average. 


\section{Statistical Analysis of Residential Isolation}

\section{Immigrant Communities' Net Propensity to Live in Isolation}

We compared the standardized modified isolation indexes $S M I_{c}$, which are derived from the intercept value $\left(\mathrm{SI}_{\mathrm{c}}\right.$,) of the models (Appendix 2), to measure the propensity to live isolated of communities for a similar profile. That profile corresponds to the reference categories of the independent variables, which are those living in a household where the breadwinner is a male immigrant arrived in Canada between 1981 and 1990, aged 30 to 34 years old, has a university degree, is bilingual and has an income in the third quintile. The $S M I_{c}$ in relation to the gross modified isolation index $M I_{c}$ shows the effect of the composition of the population on the isolation (Fig. 1).

These results show that no communities are hyperisolated in the Montréal metropolitan area; this supports Apparicio's observations (2006). Indeed, the most isolated communities have modified isolation $(M I)$ indices only slightly higher than 0.10 ; the scale goes up to 1. In comparison, Johnston et al. (2004) showed that $M I$ indices can exceed 0.5 for "Black" communities in some American metropolitan areas; the mean was 0.253 in 1980 and 0.208 in 2000 . However, in contexts where many immigrant communities coexist in the same neighborhoods, a non-isolated community could still have little residential proximity to the majority group.

While none of the communities we studied are hyperisolated, their levels of isolation nevertheless vary. $M I_{c}$ numbers equal to or greater than 0.1 for the Italian $(0.124)$, Filipino (0.121), Greek (0.100), and South Asian (0.100) communities, meaning that regardless of their sociodemographic compositions, these communities are the most isolated in Montréal. Conversely, the metropolitan region's least isolated communities are the South American, Romanian, and Portuguese, which have $M I_{c}$ levels below 0.02 .

Our results show that for most communities, the standardized modified index $S M I_{c}$ differs widely from the $\mathrm{MI}_{\mathrm{c}}$. Because $\mathrm{MI}_{\mathrm{c}}$ are generally out of range of the confidence interval of $S M I_{c}$, we can confirm that differences in residential isolation among

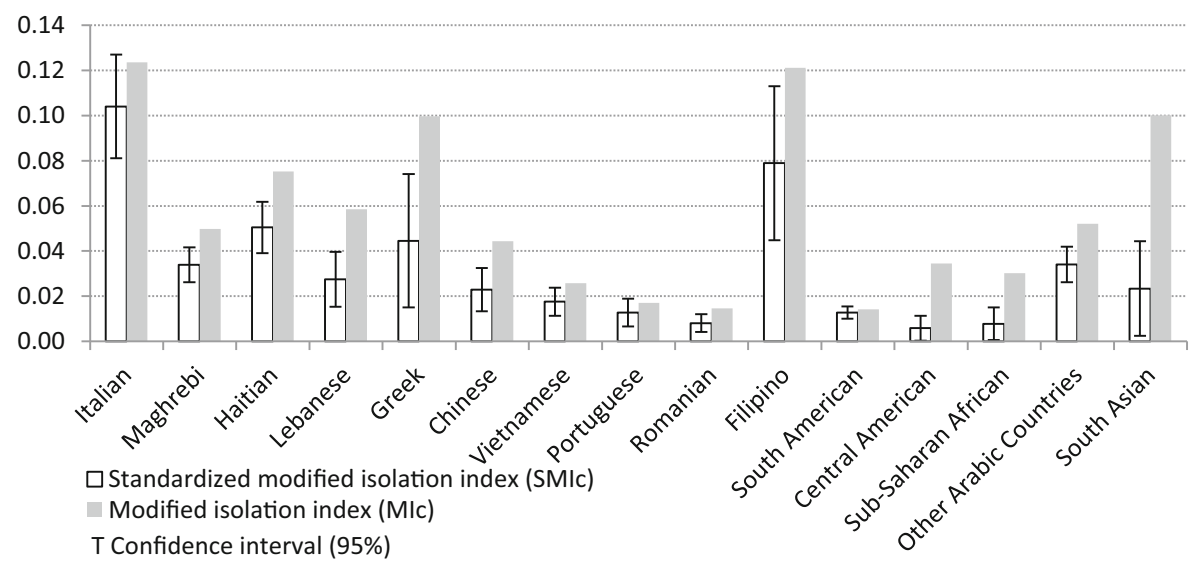

Fig. 1 Standardized modified isolation index compared to modified isolation index of immigrant communities, Montréal metropolitan region, 2011. Source: 2011 National Household Survey; Author's calculations 
communities are partly explained by differences in their socioeconomic compositions and/or the differential behaviors of some subgroups. For instance, the $S M I_{c}$ of Greeks (0.045) and South Asians (0.023) are much smaller than their corresponding $M I_{c}$; these communities do not statistically differ anymore from others when wecompared the isolation of the reference profile. The $M I_{c}$ of Central Americans (0.035) and SubSaharan Africans (0.030) are low, and their $S M I_{c}$ even lower $(0.006$ and 0.008 , respectively). Considering the condifence interval, this suggests that segregation in terms of residential isolation is almost nonexistent for the reference profile of these communities. On the other hand, the $\mathrm{SMI}_{\mathrm{c}}$ for Haitians and Italians are quite similar to their $\mathrm{MI}_{\mathrm{c}}$ and these communities remain more isolated than others. Indeed, the Italian community is the only one with a standardized index above 0.10 .

\section{Individual Determinants for Immigrant Communities to Live in Isolation}

The independent variables of these models have divergent effects on the propensities of Greater Montréal's immigrant communities to live in isolation. Detailed parameters (estimated from models) are presented in Appendix 2.

Gender only significantly affecsd the propensity to live in isolation in the Central American, Lebanese, and Maghrebi communities. For Central American Lebanese communities, members living in households where the breadwinner is a women are more likely to live in isolation than those with a male breadwinner, according to the parameters associated with that category $(0.006$ and 0.010 , respectively). This relationship is reversed in the Maghrebi community, in which female breadwinners are a little less likely to live in isolation $(-0.004)$ than males. However, considering the weak magnitude of these parameters, the effect of gender on the isolation index remained low. In the other communities we studied, this variable is not statistically significant. Breadwinner age has little effect in most communities, except for those from "other Arabic countries", in which the parameters clearly show that the propensity to live in isolation increases with age.

Our regression models show that time of arrival is an important factor in communities' levels of isolation. According to the spatial assimilation theory (Massey and Denton 1985), immigrants tend to live in segregated neighborhoods for their first few years in a new country and adopt the residential behaviors of natives after their assimilation (and in later generations). Thus, we could expect to observe a negative relation between people's propensity to live in isolation and the number of years since their arrival - and also a lower propensity for isolation in second generations. In Fig. 2, we illustrate the parameters of this variable for communities in which this relationship is both significant and conclusive. ${ }^{2}$ We used those who arrived between 1981 and 1990 as a reference category (parameter $=0$ ). All other parameters must be analyzed in relation to that category.

As illustrated in Fig. 2, we observ the expected pattern in Filipino, Lebanese, South Asian, and Sub-Saharan African communities. However, the amplitude of this effect differs; the difference between arrival periods is much more important for the South Asian community than the Sub-Saharan African and Lebanese communities, for which the statistical significance of the pattern is not concluent. We also observ the expected

${ }^{2} p<0.05$ for most of categories 


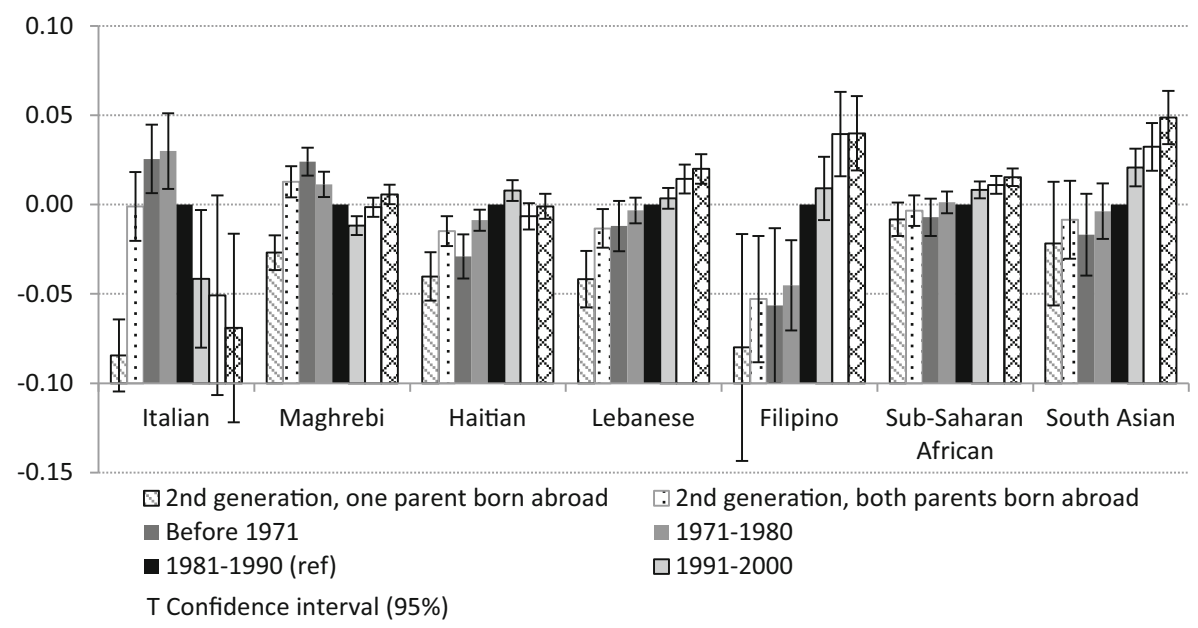

Fig. 2 Effect of immigrants' arrival periods and generational status on the proportion of the same immigrant community living in the neighborhood, Montréal metropolitan region, 2011. Source: 2011 National Household Survey; Author's calculations

pattern in Haitians, but only in the older waves of immigrants and second generations; there is no significant difference of parameters for immigrants who arrived after 1981.

In Italians, we observe the opposite pattern of what expected by the spatial assimilation theory. Those living in a household where the breadwinner arrived before 1981 have much higher propensities to live in isolation, with parameters above 0.03 . However, the low number of Italians arrived past 1990 reduces the statistical significance for recent cohorts. There is also an significant gap in the second generation between those with two parents born abroad and those with only one parent born abroad. Those with only one foreign-born parent are much less likely to live in isolation. However, this result doesn't mean that this community tend to live more in isolation following years spent in Canada. This is probably due to different behaviors between cohorts. A large proportion of Italians immigrated before 1971, when the social and political context in Montréal was very different. Since the 70s, several policy changes have affected the behaviors of immigrants, in particular the provincial repatriation of immigration selection, the selection of immigrants according to their economic and social capital, and regulations on language and diversity. Thus, we cannot assume that recent immigrants (very few in the Italian case) will have the same behaviors as earlier ones.

The Maghrebi community exhibits an intriguing dynamic. Although their trend in residential isolation follows the spatial assimilation theory pattern for those who arrived after 1991, we observed specific behaviors that increase isolation in older immigrants. Moreover, second generation immigrants whose parents were both born abroad demonstrated a higher propensity to live in isolation $(0.01)$; this effect is much lower in those who had only one foreign-born parent $(-0.027)$.

In other communities, the relationship between their period of arrival and the propensity to live in isolation is not significant. However, this doesn't necessarily contradict the spatial assimilation theory, which also takes into account the immigrants' income; this tends to increase over people's years of residence in the country. This 
situation can be seen in the case of the Central American community. For them, the relationship between their propensity to live in isolation and their period of arrival is not significant. However, we observ a clearly significant and negative relationship with income (Fig. 3). For these specific communities, income is more important than period of arrival, although both are related. In communities whose period was significant, income also had an effect. Thus, the combined effect of isolation is very high for newcomers and the very poorestspecifically South Asians and Filipinos.

Although income is related to education, our models distinguish the effects of these two variables. The overall relation is the same: more educated people are less likely to live in isolation than less educated people (as illustrated in Fig. 4). However, the amplitude of this effect is not the same between communities (and is not significant for some of them). This effect is much higher for Italians, Haitians, Greeks, and South Asians, with parameters above 0.25 for less educated people as compared to people with a bachelor's degree level of education or higher. This relationship is significant, but smaller, in the Lebanese, Portuguese, Vietnamese, and Central American communities. It's not relevant to the other communities we studied.

The effect of family structure on the propensity to live in isolation is relatively low. However, there is a significant effect in the category "couples with children", which has an increased propensity to live in isolation compared to couples without children-especially in the Italian (0.02) and Greek communities (0.015). This exists in lower proportions (but is still significant) in people from Maghreb (0.008), Lebanon (0.009), Vietnam (0.006), Central America (0.006), and Sub-Saharan Africa (0.005). Single family parents only appear to be more likely to live in isolation in South (0.002) and Central American (0.007), Sub-Saharan African (0.006), Lebanese (0.012), and Vietnamese $(0.008)$ communities, though these parameters are quite low.

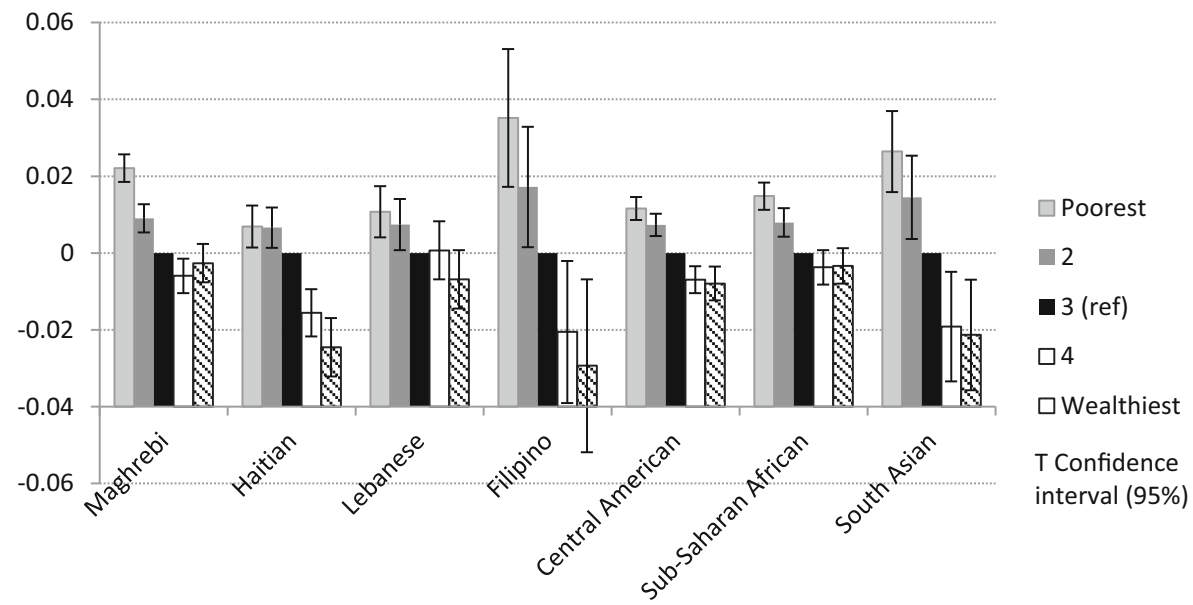

Fig. 3 Effect of income quintiles on the proportion of the same immigrant community living in the neighborhood, Montréal metropolitan region, 2011. Source: 2011 National Household Survey; Author's calculations 


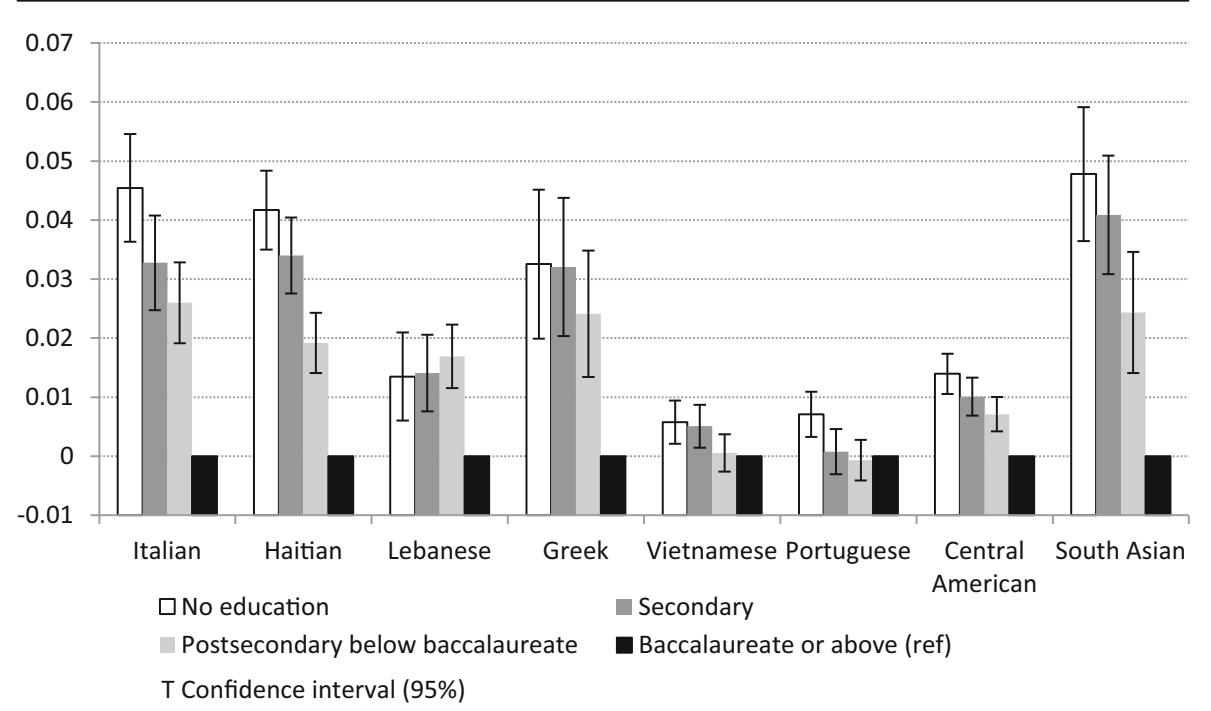

Fig. 4 Effect of education on the proportion of the same immigrant community living in the neighborhood, Montréal metropolitan region, 2011. Source: 2011 National Household Survey; Author's calculations

The last independent variable in our analysis, the knowledge of Canada's official languages, French and English, has an effect on most groups' propensities to live in isolation, except for the Sub-Saharan African, South American, and Vietnamese communities. The isolation is much higher in those who do not understand either of Canada's official languages than in those who know both of them in the Italian (0.035) Greek (0.042), and South Asian (0.032) communities. This effect is smaller, but still significant, in the Portuguese (0.009) and Chinese (0.007) communities.

\section{Identification of Specific Isolated Profiles}

Combining the different parameters of the previous statistical analysis in regard to the crossed effectives of the categories, we can identify profiles that are more likely to live in isolation and which could have policy-concerns.

\section{Haitian Refugees}

The $S M I_{c}$ for Haitian community was not among the highest we observed, but was still appreciable (0.050). The reference profile concerned with the $S M I_{c}$ are those with bachelor degree levels of education or higher. Statistical analysis revealed that the propensity to live in isolation is much lower for those who live in households where breadwinner has secondary level educations $(+0.034)$ or less (0.042). This represents about the third of the Haitian community. Furthermore, we noted that those who arrived before 1981 were much less likely to live in isolation. Thus, a first profile with a high propensity to live in isolation can be described: Haitians who arrived in 1981 or later and have a 
secondary level of education or less. This profile probably represents people living in households in which the breadwinner is a Haitian that immigrated as a refugee or dependent, which corresponds to minimal education levels. This profile represents about 25,000 people (21.5\% of the Haitian community).

\section{Italians with Low Education Levels who Arrived before 1981}

Although the $S M I_{c}$ for the Italian community was the highest of all the communities we studied, it corresponds to a reference profile in which period of arrival is between 1981 and 1990. Statistical analysis reveals that the propensity for living in isolation is much higher in those who arrived before $1971(+0.026)$ and between 1971 and $1980(+0.030)$, which represents $41.1 \%$ of the Italian community. Another specific individual characteristic that significantly increases their propensity for living in isolation is education; very high parameters are observed for those with a secondary level of education $(+0.033)$ or less $(+0.045)$. They represent an important part of the community (44.6\%). This second profile corresponds to Italians who arrived before changes in selection process of immigrant workers based on social capital. This group includes 46,000 people. Many of the Italians that arrived during this period have sponsored a family member. These people are among the oldest still-alive waves of immigration. Because they are the wealthiest immigrants group, the residential dynamic of resurgent ethnicity could probably explain this higher residential isolation.

\section{Greeks with Low Education Levels who Arrived before 1981}

The $S M I_{c}$ of Greeks was quite high (0.058). Less-educated Greeks, who are very numerous (53.2\% have a secondary level or less), were much more likely to living in isolation $(+0.032 /+0.033)$. Though their period of arrival is not significant, very few of them arrived after 1981 (3.7\%). Thus, a third profile can be identified: Greeks with low levels of education who arrived before 1981, which represents 18,900 people (36.7\% of the Greek community).

\section{Low-Income Maghrebis}

Many Maghrebis have recently arrived in Montréal (58.0\% arrived after 2000). Although they are educated (they were selected for immigration based on their economic and social capital) many of them find difficulty in the labor market. This occurs for many reasons, including literacy, numeracy skills, and discrimination (Picot and Sweetman 2005; Ferrer et al. 2006; Eid 2012). Thus, a large proportion of these people are in the poorest income quintile $(37.7 \%)$; they also present the highest propensity to live in isolation (as revealed in our statistical analysis). Thus, the moderated $S M I_{c}$ for the Maghrebi community (0.034), which concerns the third quintile, became much higher for the poorest $(+0.022)$ in this group. Because Maghrebis are a very important recent immigrant groups and expected forthcoming ones, this specific profile's isolation and housing situations are policy-concerns. Our specific analysis of these 
communities calls for a more detailed analysis of the Maghrebi community's level of integration and residential strategies.

\section{Filipinos who Arrived via the Live-in Caregivers Program}

Statistical analysis of their isolation levels reveals that Filipinos are the most likely of the groups we studied to live in isolation, as illustrated by their $S M I_{c}$ (0.079), the second highest we studied. Moreover, this propensity is much higher in those living in households in which breadwinners had arrived within the last 10 years (+0.039 for those arrived between 2001 and 2006 and +0.040 for those arrived after 2006) and for those in the two poorest income quintiles $(+0.035$ and +0.017$)$. We observed 2440 Filipinos who arrived in 2001 or later and whose income was in the two poorest quintiles ( $8 \%$ of the community). Although they are not very numerous, this group's situation is of great policy concern. Many Filipinos in this situation are immigrants who arrived via the Live-In Caregivers program, which mainly recruits women from the Philippines (Castonguay et al. 2009). This program gives permanent residence to people who spend two years serving their employers as live-in caregivers. Following this period, they can find their own housing and sponsor their families. Although postsecondary degrees are required for acceptance into this program, many studies show that the professional, social, and economic situations of these people are quite poor (Rose and Ouellet 2000; Bilala 2013).

\section{South Asian Refugees}

South Asians have a very high $M I_{c}(0.100)$, but a much lower $S M I_{c}(0.023)$, meaning that their high isolation is mainly explained by their composition. Statistical analyses reveal a much higher propensity to live in isolation in immigrants arrived in or after 1991 (up to +0.049 for those arrived between 2006 and 2011). The propensity to live isolated is also increased in those who live in a household where the breadwinner has no bachelor degree (up to +0.048 for those who don't have secondary level), is in the two poorest income quintiles (respectively +0.026 and +0.014 ), and does not speak an official language (+0.032). These specific profile counts 28,020 individuals, a significant part of the community $(38 \%)$. This particular profile seems correspond to refugees, since they do not have characteristics that are associated with economic immigration programs.

\section{Discussion}

For most communities, the results of this study are consistent with the classical spatial assimilation model. As expected, residential isolation tended to decrease when the socioeconomic status and the number of years lived in the country increase. However, higher residential isolation levels are observed for Italians and Greeks who immigrated 
long time ago. They are wealthier than the average and also have good housing situations (Balakrishnan and $\mathrm{Wu}$ 1992), suggesting that a resurgent ethnic dynamic has been in operation.

The low standardized isolation indexes for immigrant communities suggest that discriminatory practices from real estate agents and bank institutions as well as structural barriers in the accessibility to ownership are probably lower in Montréal for immigrant communities than in American metropolitan areas. In support of this hypothesis, Marois and Bélanger (2014) also found that there is no "White Flight" in Montréal, because the propensity to move from the inner city to the suburb was the same for members of visible minority and Whites once the income, the duration of residency in Canada and the language are statistically controlled. Thus, the place stratification theory that is used to explain the residential dynamic of Afro-Americans and Hispanics in many American cities (Logan and Alba 1993; South and Crowder 1998; Pais et al. 2012 ) is probably not relevant for the residential dynamic of immigrant communities in Montréal. Additional investigation should be made in regard to the immigrants' neighborhood and the quality of their housing situation to be more conclusive.

In regard with the Maghrebis, a particular issue is revealed as the study did not find lower isolation for the second generation, as expected. This result shows the limits of the theoretical and empirical frameworks connected to residential segregation and calls for a reinvestment in "classical" experiential approaches with rigorous mixed quantitative-qualitative methods. Does this observation result from discrimination in the housing market or from persistent preferences to live in co-ethnic sectors? Apparicio et al. (2006) found that religion was a more important variable than ethnicity in the residential segregation in Montréal. In addition, Tournier (2013) reported that the second generations of Maghrebis in France were more religious than their parents and this return to religion was not related to socioeconomic status or discrimination. Although the context is not the same in Canada, the hypothesis of an increase of the religiosity in the second generation of Maghrebis could maybe explain the particular pattern observed in our study for this subpopulation. This being said, we suggest investigating residential environments far beyond merely residence locations.

From a basic perspective, we found that many individual characteristics strongly impact the residential isolation and that the effects are not always the same between different immigrant communities. For instance, our models showed that the income quintile is a very important determinant of the residential isolation level in the Philippian and South Asian communities, while this variable was not significant for some others such as the Chinese and Vietnamese communities. Similarly, the isolation level differed widely when considering education in the Haitian and South Asian communities, but the amplitude was much smaller in the Vietnamese and Portuguese communities. Isolation and integration process are realities that vary according to specific cultures of origin and possibilities for mobilizing social capital. When studying residential trajectories and location, considering immigrant communities as a whole could hide particular dynamics of subpopulations. This is particularly important to 
consider when the immigrant population is very heterogeneous like in Montréal and many other North-American metropolises. The individual determinants based approach used in this study allowed identifying specific profiles, such as the low-income Maghrebis and the Haitian refugees, for which the higher isolation would be diluted in the low isolation index observed in their whole community.

The statistical approach used in this study can only measure the residential segregation under the dimension of isolation. However, other dimensions also exist, such as equality, concentration and spatial aggregation, which all have relevance for measuring different spatial dynamics, those bring into play contrasted integration processes. Although Apparicio et al. (2006) found that all these dimensions have low segregation levels in Montréal for immigrant communities, further works should investigate this kind of analysis for specific profiles, such as those identified in our study.

\section{Conclusion}

Our analysis confirms that there are no hyperisolated immigrant communities in Montréal. The statistical method used in this study however shows that propensity to live in isolation varies between communities. The estimated parameters also allow positing that people in certain profiles are much more likely to live in isolation. Moreover, some of these people have vulnerable socioeconomic characteristics. Among them, Filipinos who arrived via the Live-In Caregivers program are of particular concern; they often face poverty and isolation. However, isolation is not always correlated with poor housing conditions. Furthermore, the absence of isolated communities does not mean that Montréal does not have neighborhoods with very high levels of ethnic concentration. The question of the interaction with native communities should also be investigated. These fingings led us to research perspectives on integration trajectories for housing markets and residential conditions.

Lived and used environments (segregated or not) can be jointly studied to aid in the understanding of the structures and mechanisms underlying segregated logics. Such work facilitates advances in the analysis of residential concentration beyond the notions of "social belonging" and "social-spatial proximity". The next step is to go beyond spatial concentration and investigate behaviors. Consequently, immigrants' spatial concentrations do not explain their levels of integration. This allows for the prediction of processes that lead to integration - both in terms of socio-spatial patterns and rules. This being said, spatial concentration is nonetheless helpful in reading social and spatial environments in which migrants' experiences can be assessed and explored.

In the next steps of our research, we will contribute to the general hypothesis that immigration is a dynamic urban development lever. If immigration changes a host society, it also changes cities (Germain et al. 2012). Montréal provides a basic example of this mechanism, due to its unique demographics. We will also explore issues of "migrant home" to increase the fundamental knowledge of the concept of "home" and its wider impacts on social and spatial integration.

Acknowledgements Open access funding provided by International Institute for Applied Systems Analysis (IIASA). 


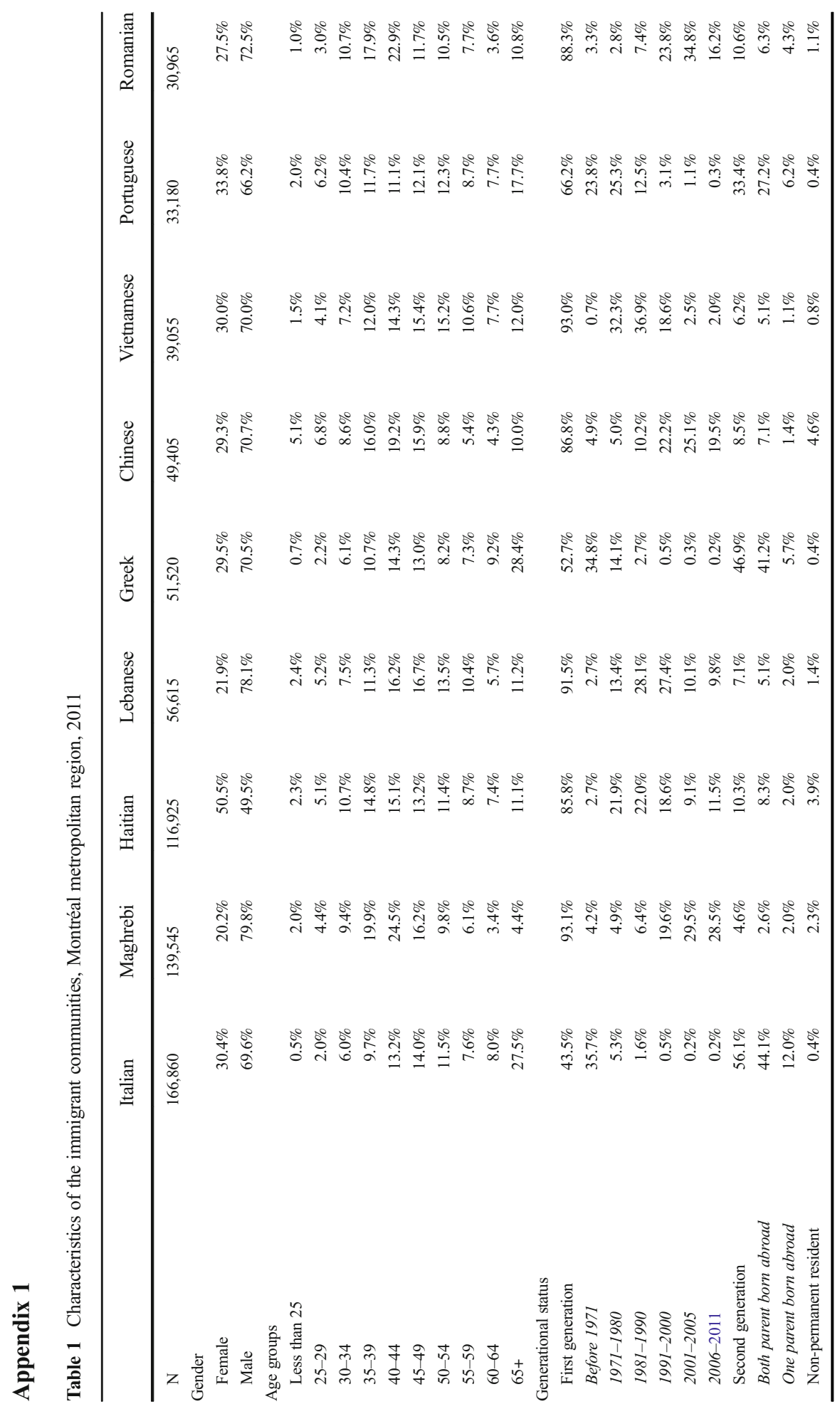




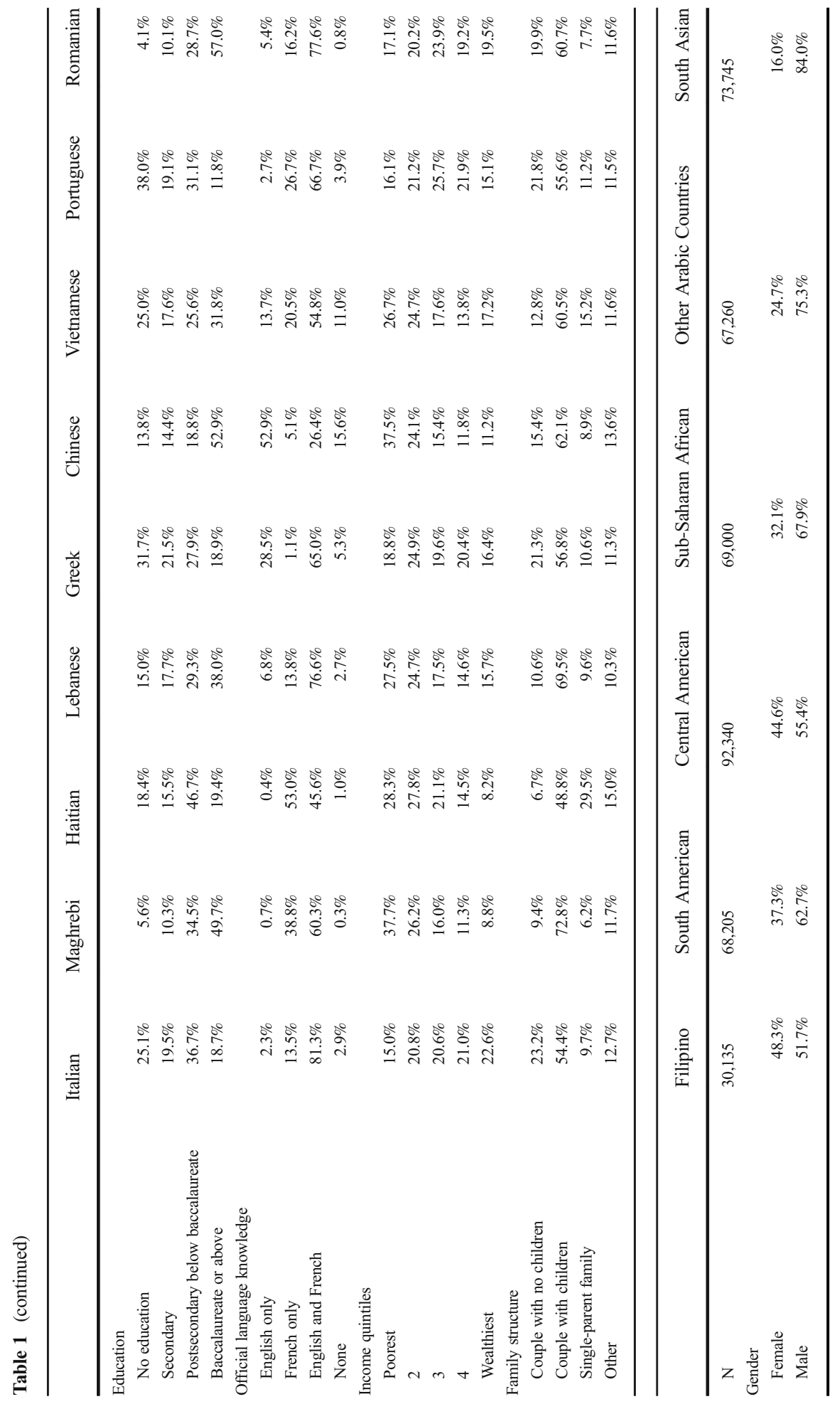




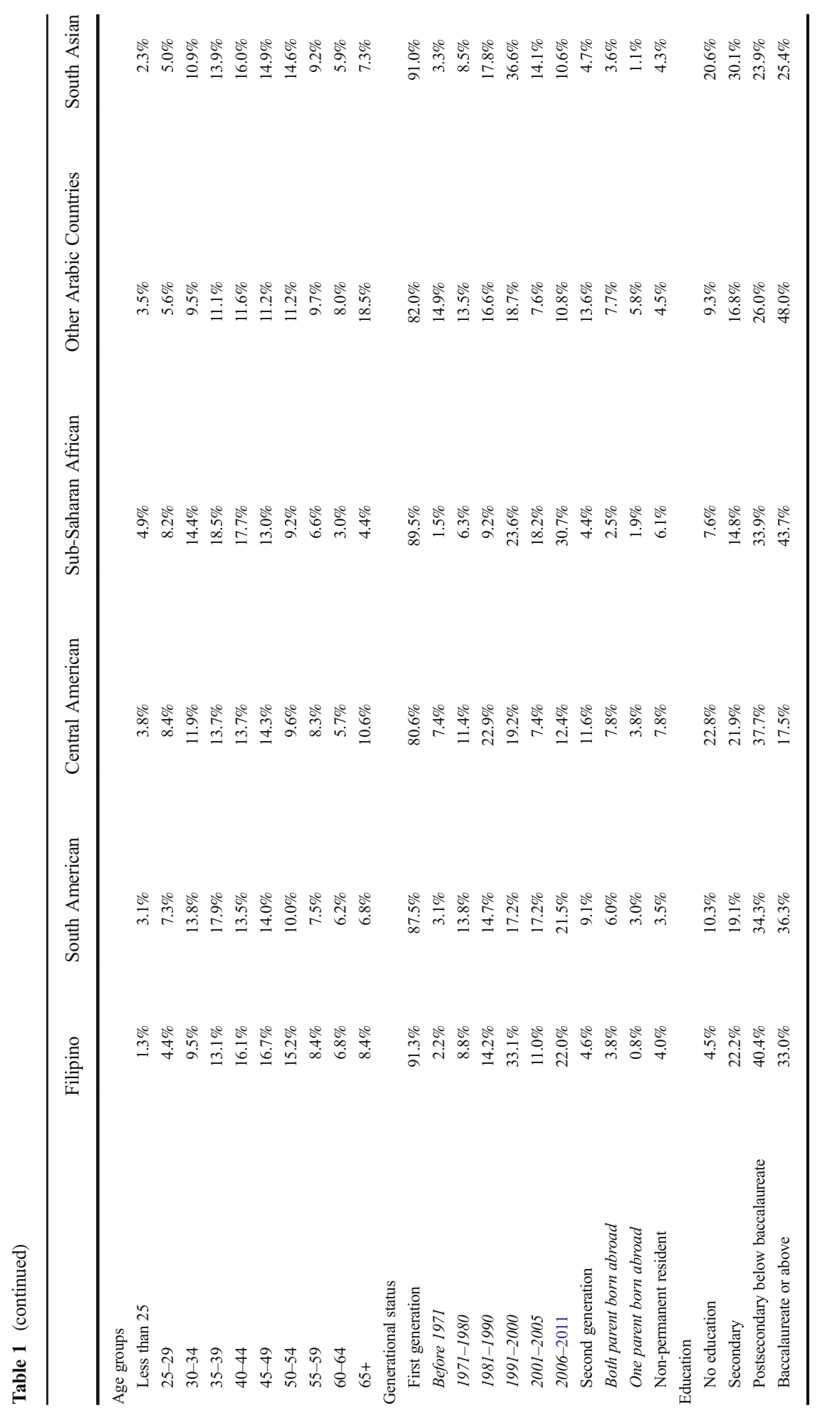




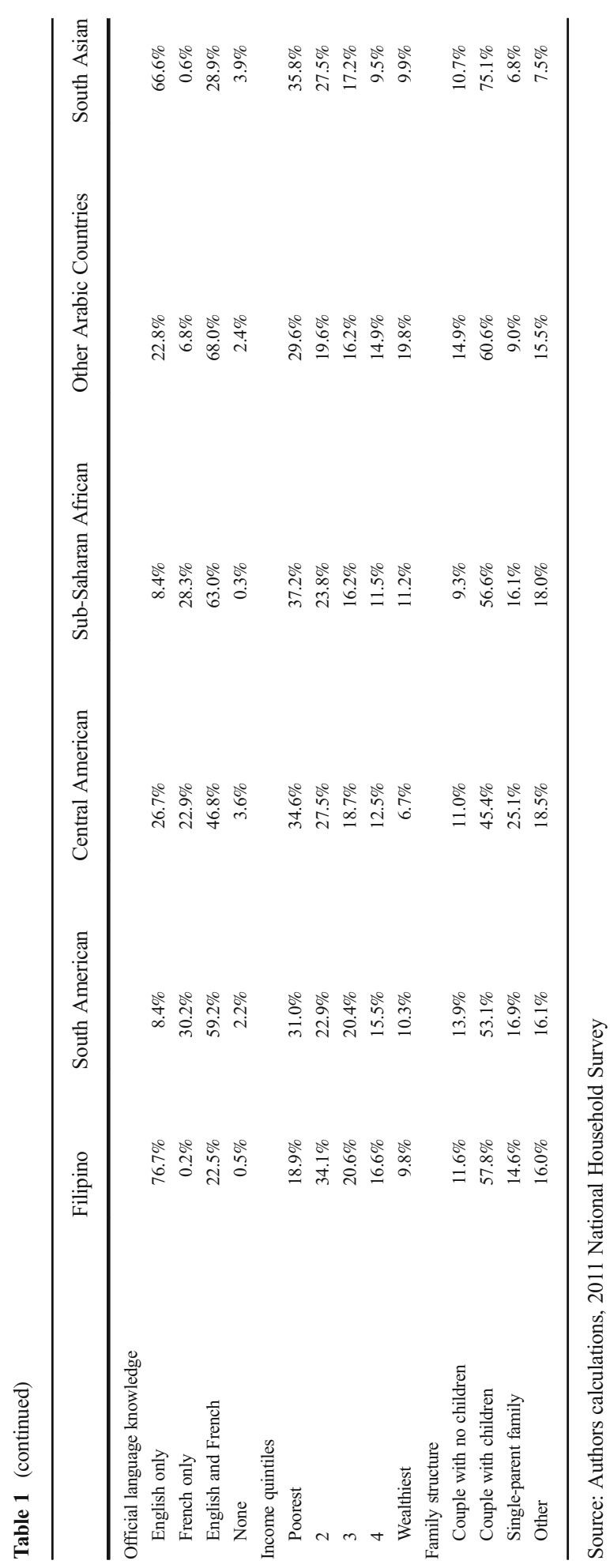




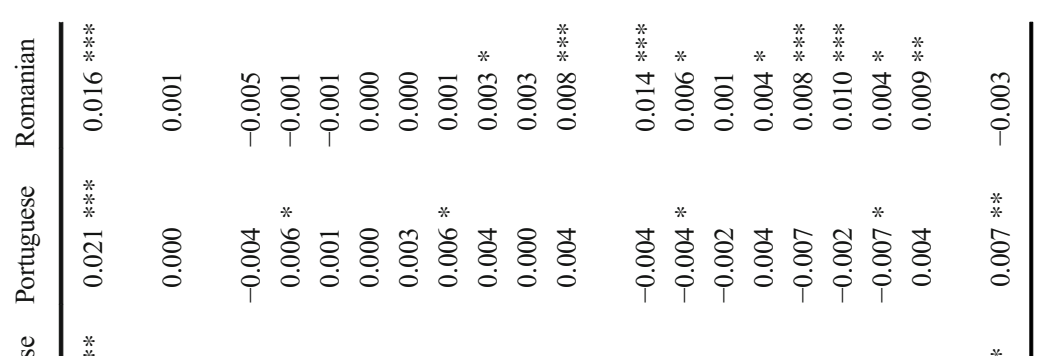

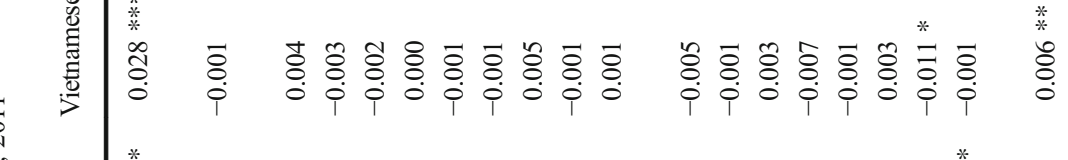

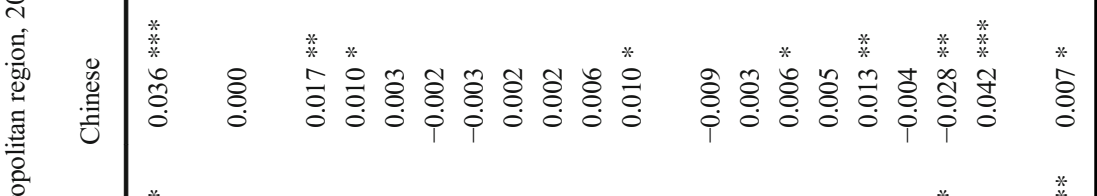

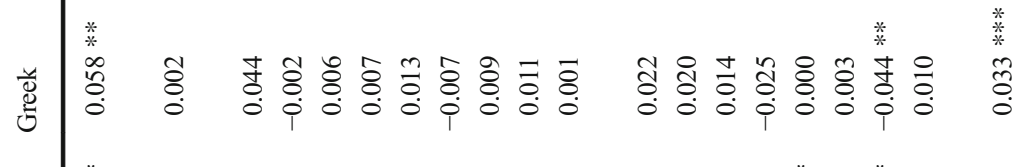

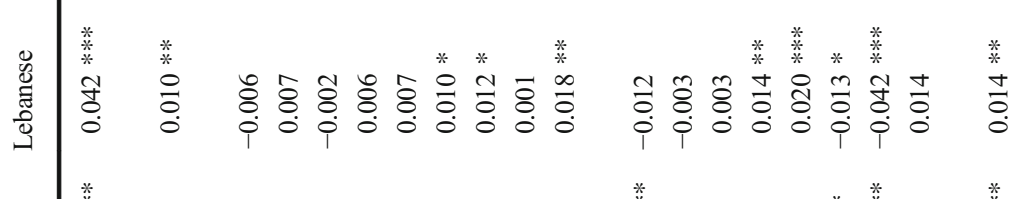

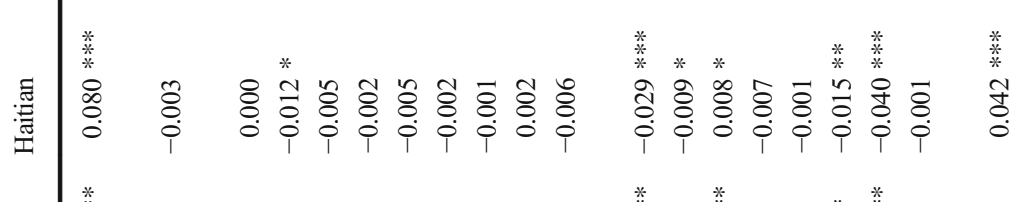

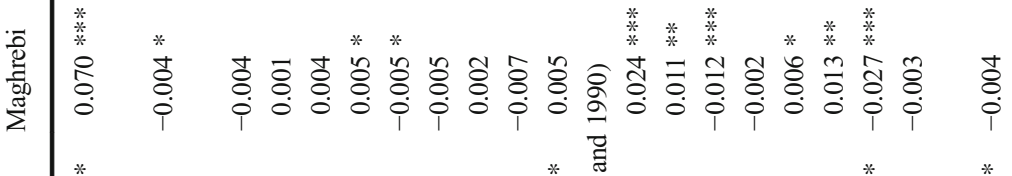

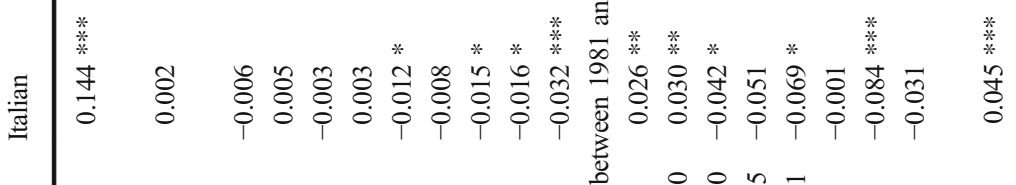

ত

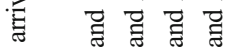

言

ขे चี

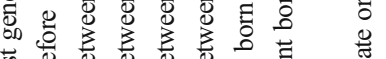

屯

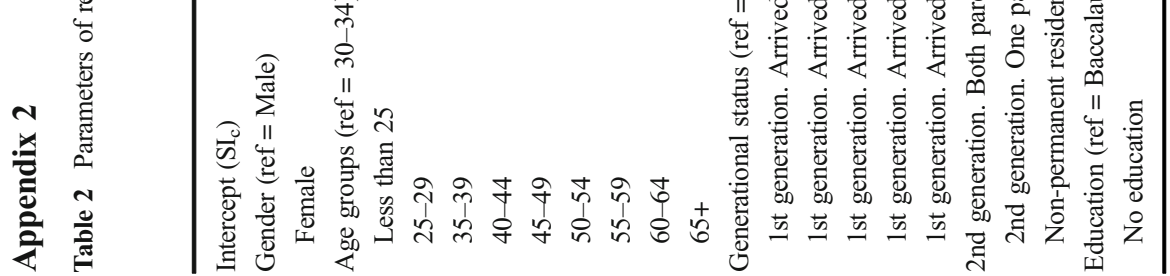




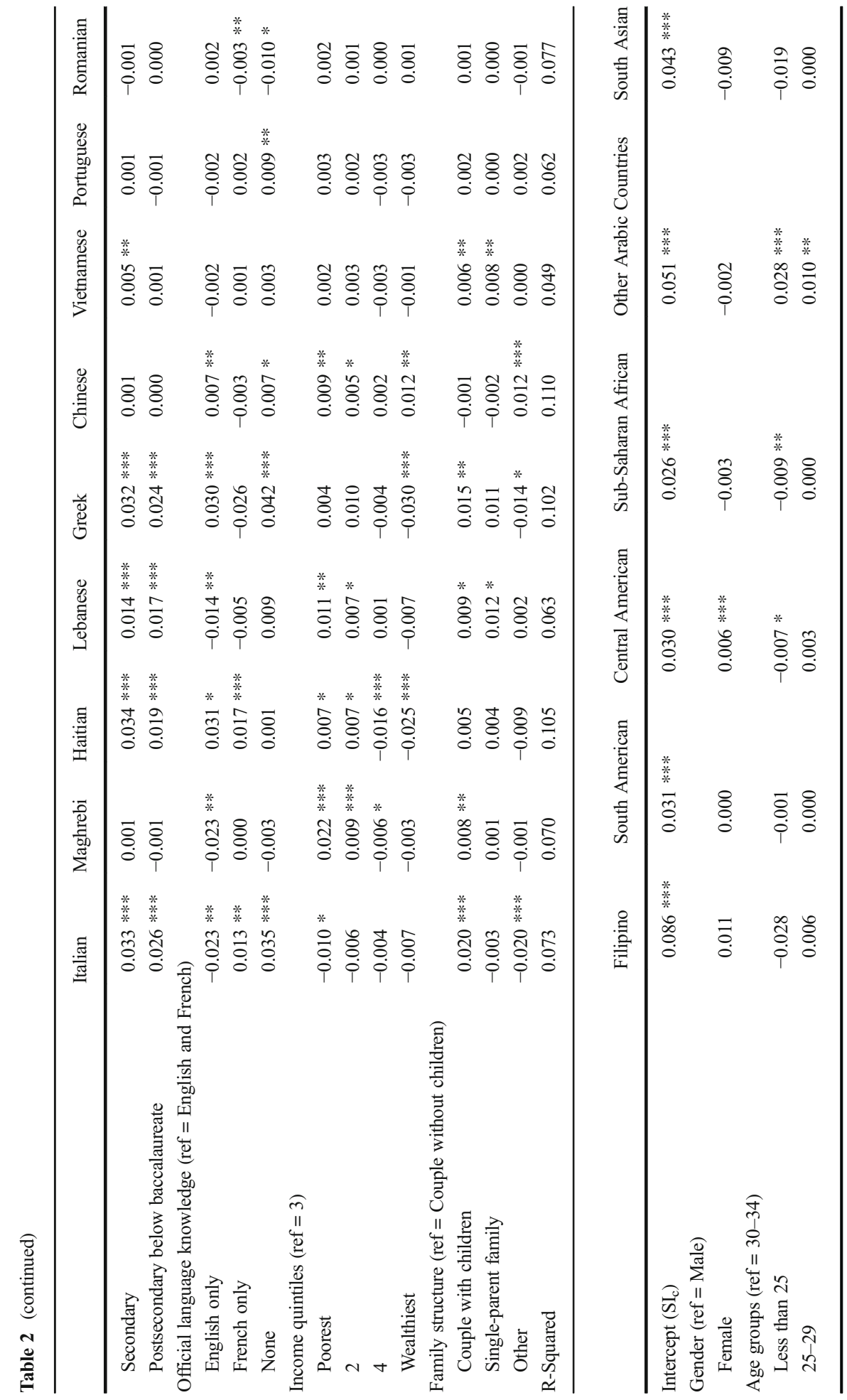




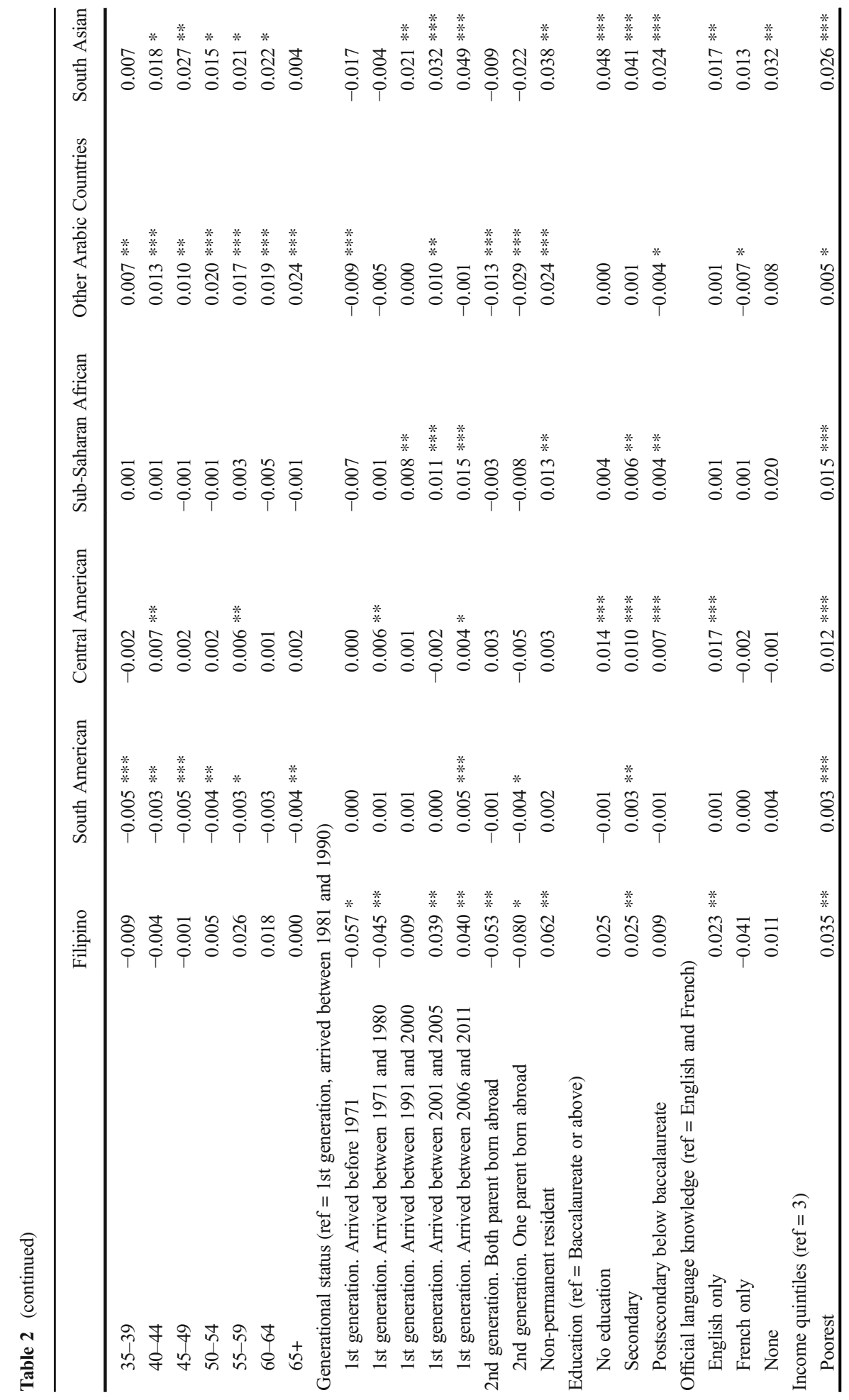




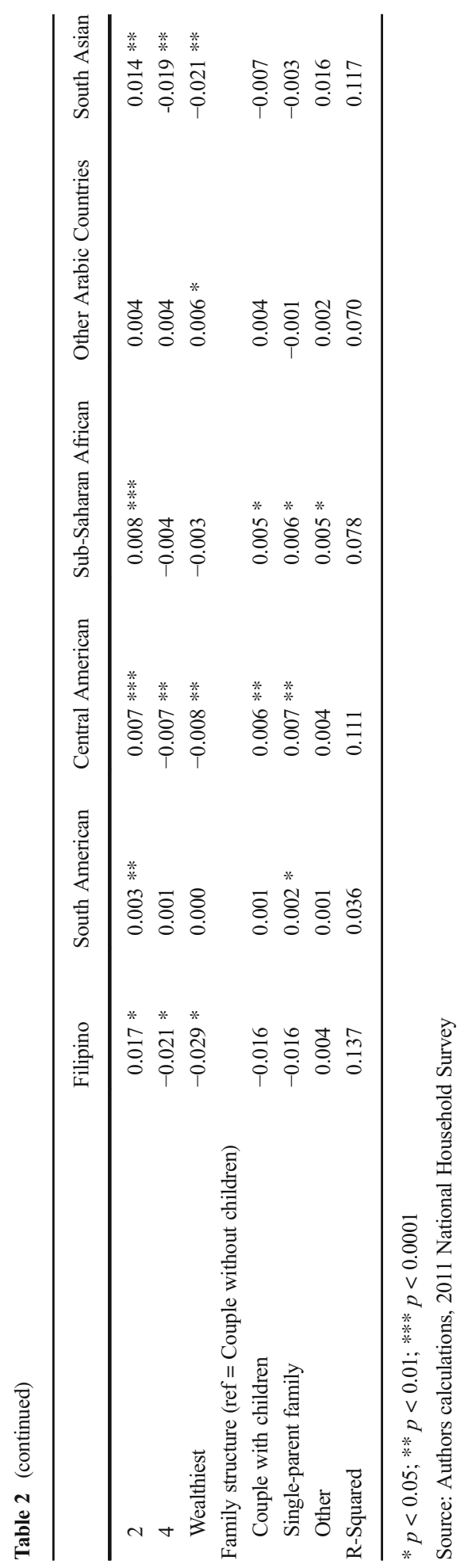


Open Access This article is distributed under the terms of the Creative Commons Attribution 4.0 International License (http://creativecommons.org/licenses/by/4.0/), which permits unrestricted use, distribution, and reproduction in any medium, provided you give appropriate credit to the original author(s) and the source, provide a link to the Creative Commons license, and indicate if changes were made.

\section{References}

Alba, R. D., \& Logan, J. (1992). Analyzing locational attainments: Constructing individual-level regression models using aggregate data. Sociological Methods \& Research, 20(3), 367-397. doi:10.1177 /0049124192020003005.

Andersen, H. S. (2010). Spatial assimilation in Denmark? Why do immigrants move to and from multi-ethnic Neighbourhoods? Housing Studies, 25(3), 281-300. doi:10.1080/02673031003711451.

Apparicio, P. (2000). Les indices de ségrégation résidentielle : un outil intégré dans un système d'information géographique. Cybergeo: European Journal of Geography, 134.

Apparicio, P., \& Séguin, A.-M. (2002). La division de l'espace residential montréalais en fonction de la langue maternelle : Apport des indices de segregation. Canadian Journal of Urban Research, 11(2), 265-297.

Apparicio, P., Leloup, X., \& Rivet, P. (2006). La répartition spatiale des immigrants à Montréal : apport des indices de ségrégation résidentielle (Vol. Publication $\mathrm{IM}-\mathrm{n}^{\circ} 28$ ): Centre de recherche interuniversitaire de Montréal sur l'immigration, l'intégration et la dynamique urbaine.

Balakrishnan, T. R., \& Hou, F. (1999). Socioeconomic integration and spatial residential patterns of immigrant groups in Canada. Population Research and Policy Review, 18(3), 201-217. doi:10.1023 /a:1006118502121.

Balakrishnan, T. R., \& Wu, Z. (1992). Home ownership patterns and ethnicity in selected Canadian cities. The Canadian Journal of Sociology / Cahiers canadiens de sociologie, 17(4), 389-403. doi:10.2307 13341216.

Bell, W. (1954). A probability model for the measurement of ecological segregation. Social Forces, 32(4), 357-364. doi:10.2307/2574118.

Bilala, D.-V. (2013). Tout accepter pour la résidence permanente. L'obligation de résidence chez l'employeur imposée par le PAFR : une entrave au droit à la liberté et à la sécurité de la personne des travailleuses: Publibook.

Borjas, G. J. (2002). Homeownership in the immigrant population. Journal of Urban Economics, 52(3), 448476. doi:10.1016/S0094-1190(02)00529-6.

Bourdieu, P. (1979). Les trois états du capital culturel. Actes de la recherche en sciences sociales, 30(1), 3-6.

Bourdieu, P. (2000). Les structures sociales de l'économie. Paris: Éditions du Seuil.

Brown, L. A., \& Chung, S.-Y. (2006). Spatial segregation, segregation indices and the geographical perspective. Population, Space and Place, 12(2), 125-143. doi:10.1002/psp.403.

Brown, L. A., \& Chung, S.-Y. (2008). Market-led pluralism: Rethinking our understanding of racial/ethnic spatial patterning in U.S. cities. Annals of the Association of American Geographers, 98(1), 180-212. doi:10.1080/00045600701734612.

Brun, J., Rhein, C., \& Bernand, C. (1994). La ségrégation dans la ville: concepts et mesures: Editions L'Harmattan.

Canada, S. (2013). 2011 National Household Survey. Ottawa: Statistique Canada.

Castonguay, M.-H., Henry, I., \& Benzakour, C. (2009). Insertion socioprofessionnelle des aides familiales résidantes. Insertion socioprofessionnelle des aides familiales résidantes: Ministère de l'Immigration et des Communautés culturelles du Québec.

Charles, C. Z. (2003). The dynamics of racial residential segregation. Annual Review of Sociology, 29(1), 167207. doi:10.1146/annurev.soc.29.010202.100002.

Chung, S.-Y., \& Brown, L. A. (2007). Racial/ethnic residential sorting in spatial context: Testing the explanatory Frameworks1. Urban Geography, 28(4), 312-339. doi:10.2747/0272-3638.28.4.312.

Cort, D. A. (2011). Reexamining the ethnic hierarchy of locational attainment: Evidence from Los Angeles. Social Science Research, 40(6), 1521-1533. doi:10.1016/j.ssresearch.2011.07.003.

Cutler, D. M., Glaeser, E. L., \& Vigdor, J. L. (2008). When are ghettos bad? Lessons from immigrant segregation in the United States. Journal of Urban Economics, 63(3), 759-774. doi:10.1016/j. jue.2007.08.003. 
Dunn, K. M. (1998). Rethinking ethnic concentration: The case of Cabramatta, Sydney. Urban Studies, 35(3), 503-527. doi:10.1080/0042098984880.

Eid, P. (2012). Les inégalités “ethnoraciales” dans l'accès à l'emploi à Montréal : le poids de la discrimination. Recherches sociographiques, 53(2), 18-21.

Faist, T. (2000). The volume and dynamics of international migration and transnational social spaces. Oxford: Oxford University Press.

Ferrer, A., Green, D. A., \& Riddell, W. C. (2006). The effect of literacy on immigrant earnings. Journal of Human Resources, XLI(2), 380-410. doi:10.3368/jhr.XLI.2.380.

Fitoussi, J.-P., Laurent, É., \& Joël, M. (2004). Ségrégation urbaine et intégration sociale. Paris: La Documentation française.

Fong, E., \& Chan, E. (2010). The effect of economic standing, individual preferences, and co-ethnic resources on immigrant residential clustering1. International Migration Review, 44(1), 111-141. doi:10.1111 j.1747-7379.2009.00800.x.

Fong, E., \& Gulia, M. (1999). Differences in neighborhood qualities among racial and ethnic groups in Canada. Sociological Inquiry, 69(4), 575-598. doi:10.1111/j.1475-682X.1999.tb00887.x.

Galea, S., \& Ahern, J. (2005). Distribution of education and population health: An ecological analysis of new York City neighborhoods. American Journal of Public Health, 95(12), 2198-2205.

Germain, A., Rose, D., \& Richard, M. (2012). Les banlieues de l'immigration ou quand les immigrants refont les banlieues. In D. Fougère (Ed.), Histoire de Montréal et de sa région (pp. 1107-1142). Québec: Presses de l'Université Laval.

Glikman, A., \& Semyonov, M. (2012). Ethnic origin and residential attainment of immigrants in European countries. City \& Community, 11(2), 198-219. doi:10.1111/j.1540-6040.2012.01398.x.

Greene, W. H. (1997). Econometric analysis. Upper Saddle River: Prentice Hall.

Hall, M. (2013). Residential integration on the new frontier: Immigrant segregation in established and new destinations. Demography, 50(5), 1873-1896. doi:10.1007/s13524-012-0177-x.

Iceland, J., \& Scopilliti, M. (2008). Immigrant residential segregation in U.S. metropolitan areas, 1990-2000. [journal article]. Demography, 45(1), 79-94. doi:10.1353/dem.2008.0009.

Iceland, J., \& Wilkes, R. (2006). Does socioeconomic status matter? Race, class, and residential segregation. Social Problems, 53(2), 248-273. doi:10.1525/sp.2006.53.2.248.

Institut de la statistique du Québec. (2015). Migrations internationales et interprovinciales. Québec, par région métropolitaine, 2001-2014.

Johnston, R., Forrest, J., \& Poulsen, M. (2002). Are there ethnic enclaves/ghettos in English cities? Urban Studies, 39(4), 591-618. doi:10.1080/00420980220119480.

Johnston, R., Poulsen, M., \& Forrest, J. (2004). The comparative study of ethnic residentinal segregation in the USA, 1980-2000. Tijdschrift voor Economische en Sociale Geografie, 95(5), 550-569. doi:10.1111 /j.0040-747X.2004.00339.x.

Johnston, R., Poulsen, M., \& Forrest, J. (2005). On the measurement and meaning of residential segregation: A response to Simpson. Urban Studies, 42(7), 1221-1227. doi:10.1080/00420980500122010.

Karsten, S., Felix, C., Ledoux, G., Meijnen, W., Roeleveld, J., \& Van Schooten, E. (2006). Choosing segregation or integration?: The extent and effects of ethnic segregation in Dutch cities. Education and Urban Society, 38(2), 228-247. doi:10.1177/0013124505282606.

van Kempen, R., \& şule Özüekren, A. (1998). Ethnic segregation in cities: New forms and explanations in a dynamic world. Urban Studies, 35(10), 1631-1656. doi:10.1080/0042098984088.

Logan, J. R. (2013). The persistence of segregation in the 21st century metropolis. City \& Community, 12(2), 160-168. doi:10.1111/cico.12021.

Logan, J. R., \& Alba, R. D. (1993). Locational returns to Human capital: Minority access to suburban community resources. Demography, 30(2), 243-268. doi:10.2307/2061840.

Logan, J. R., Alba, R. D., McNulty, T., \& Fisher, B. (1996). Making a place in the metropolis: Locational attainment in cities and suburbs. Demography, 33(4), 443-453.

Logan, J. R., Zhang, W., \& Alba, R. D. (2002). Immigrant enclaves and ethnic communities in New York and Los Angeles. American Sociological Review, 67(2), 299-322. doi:10.2307/3088897.

Marois, G., \& Bélanger, A. (2014). De Montréal vers la banlieue : déterminants du choix du lieu de résidence. Cahiers québécois de démographie, 43(2), 439-468.

Massey, D. S., \& Denton, N. A. (1985). Spatial assimilation as a socioeconomic outcome. American Sociological Review, 50(1), 94-106. doi:10.2307/2095343.

Musterd, S., Ostendorf, W., \& Breebaart, M. (1998). Multi-Ethnic Metropolis : Patterns and Policies: Kluwer academic publishers.

Myles, J., \& Hou, F. (2003). Établissement réussi et ségrégation résidentielle parmi les minorités visibles de Toronto. Ottawa: Statistique Canada. 
Pais, J., South, S. J., \& Crowder, K. (2012). Metropolitan heterogeneity and minority neighborhood attainment: Spatial assimilation or place stratification? Social Problems, 59(2), 258-281. doi:10.1525 /sp.2012.59.2.258.

Park, R. E., \& Burgess, E. W. (1925). The city. Chicago: University of Chicago Press.

Peleman, K. (2002). The impact of residential segregation on participation in associations: The case of Moroccan women in Belgium. Urban Studies, 39(4), 727-747. doi:10.1080/00420980220119543.

Pelletier, D. (2012). Accéder au meilleur quartier possible : types de famille et ségrégation résidentielle croisée à Montréal. Cahiers québécois de démographie, 41(2), 257-298.

Picot, G., \& Sweetman, A. (2005). Dégradation du bien-être économique des immigrants et causes possibles : mise à jour 2005. Dégradation du bien-être économique des immigrants et causes possibles : mise à jour 2005. Ottawa: Études analytiques, documents de recherche sur l'analyse économique, Statistique Canada.

Rose, R., \& Ouellet, E. (2000). Une évaluation de l'emploi d'aide familiale: Recherche effectuée dans le cadre du protocole d'entente UQAM - Relais - Femmes.

Rosenbaum, E., \& Friedman, S. (2001). Differences in the locational attainment of immigrant and native-born households with children in new York City. Demography, 38(3), 337-348.

Sassen, S. (1991). The Global City. New York: Princeton University Press.

Séguin, A.-M., Rose, D., \& Mongeau, J. (2003). L'insertion résidentielle des jeunes issus de l'immigration à Montréal. SCHL: Rapport de recherche dans le cadre d'Immigration et métropoles.

Sélimanovski, C. (2008). La frontière de la pauvreté. Rennes: Presses Universitaires de Rennes.

Shihadeh, E. S., \& Flynn, N. (1996). Segregation and crime: The effect of Black social isolation on the rates of Black urban violence. Social Forces, 74(4), 1325-1352. doi:10.1093/sf/74.4.1325.

Simpson, L. (2004). Statistics of racial segregation: Measures, Evidence and policy. Urban Studies, 41(3), 661-681. doi:10.1080/0042098042000178735.

South, S. J., \& Crowder, K. D. (1998). Leaving the 'Hood: Residential mobility between Black, white, and integrated neighborhoods. American Sociological Review, 63(1), 17-26. doi:10.2307/2657474.

Spivak, A. L., Bass, L. E., \& John, C. S. (2011). Reconsidering race, class, and residential segregation in American cities. Urban Geography, 32(4), 531-567. doi:10.2747/0272-3638.32.4.531.

Tournier, V. (2013). Les musulmans en France : religiosité, politisation et capital social. Policing and Society, 32(2), 89-120.

Turner, M. A., Ross, S. L., Galster, G., \& Yinger, J. (2002). Discrimination in metropolitan housing markets: National Results from Phase 1 of the housing discrimination study (HDS). Washington, DC: Department of Housing and Urban Development.

Walton, E. (2012). Resurgent ethnicity among Asian Americans: Ethnic neighborhood context and health. Journal of Health and Social Behavior, 53(3), 378-394. doi:10.1177/0022146512455426.

Wen, M., Lauderdale, D. S., \& Kandula, N. R. (2009). Ethnic neighborhoods in multi-ethnic America, 19902000: Resurgent ethnicity in the Ethnoburbs? Social Forces, 88(1), 425-460. doi:10.1353/sof.0.0244. 